\title{
Investigating Electrode Flooding in a Flowing Electrolyte, Gas- Fed Carbon Dioxide Electrolyzer
}

\author{
McLain E. Leonard, ${ }^{[a]}$ Lauren E. Clarke, ${ }^{[a]}$ Antoni Forner-Cuenca, ${ }^{[a, b]}$ Steven M. Brown, ${ }^{[a]}$ and Fikile R. \\ Brushett ${ }^{*[a]}$
}

\begin{abstract}
Managing the gas-liquid interface within gas diffusion electrodes (GDEs) is key to maintaining high product selectivities in carbon dioxide electroreduction. By screening silver-catalyzed GDEs over a range of applied current densities, we observe an inverse correlation between carbon monoxide selectivity and the electrochemical double-layer capacitance, a proxy for wetted electrode area. We find that plotting current-dependent performance as a function of cumulative charge leads to data collapse onto a single sigmoidal curve indicating that the passage of faradaic current accelerates flooding. We hypothesize that high cathode alkalinity, driven by both initial electrolyte conditions and cathode half-reactions, promotes carbonate formation and precipitation which, in turn, facilitates electrolyte permeation. This mechanism is reinforced by the observations that post-test GDEs retain less hydrophobicity than pristine materials and that water rinsing and drying electrodes temporarily recovers peak selectivity. This knowledge offers an opportunity to design electrodes with greater carbonation tolerance to improve device longevity.
\end{abstract}

\section{Introduction}

Developing efficient carbon dioxide $\left(\mathrm{CO}_{2}\right)$ electroreduction processes, which leverage renewable electrons, can provide sustainable pathways to a range of fuels, chemicals, and plastics while also displacing anthropogenic greenhouse gas emissions. ${ }^{[1]}$ Aqueous-phase $\mathrm{CO}_{2}$ delivery has been the preferred method for evaluating electrocatalytic materials at ambient conditions $(298 \mathrm{~K}$, 1 atm). ${ }^{[2-4]}$ However, electrochemical performance in such configurations is constrained by low $\mathrm{CO}_{2}$ solubility $(33 \mathrm{mM})^{[5]}$ and diffusivity $\left(1.9 \times 10^{-5} \mathrm{~cm}^{2} \cdot \mathrm{s}^{-1}\right),{ }^{[6]}$ which, in turn, lead to mass transport limitations that set an upper limit on current density of ca. $20 \mathrm{~mA} \cdot \mathrm{cm}^{-2}{ }^{2}{ }^{7]}$ Gas-phase delivery is an alternative approach whereby $\mathrm{CO}_{2}$ is fed into an electrolysis cell through a gas diffusion electrode (GDE) whose catalyst layer $(\mathrm{CL})$ interfaces with an electrolyte layer. In this configuration, the higher diffusivity of gaseous $\mathrm{CO}_{2}\left(\sim 10^{-1} \mathrm{~cm}^{2} \cdot \mathrm{s}^{-1}\right)^{[6]}$ and the reduced diffusion lengths within the $\mathrm{CL}$ enable increased current densities, typically an order of magnitude or greater over atmospheric aqueous-phase

[a] M. E. Leonard, L. E. Clarke, Prof. Dr. A. Forner-Cuenca, Dr. S. M. Brown, Prof. Dr. F. R. Brushett

Department of Chemical Engineering

Massachusetts Institute of Technology

Cambridge, MA, 02139, USA

E-mail: brushett@mit.edu

[b] Prof. Dr. A. Forner-Cuenca

Membrane Materials and Processes

Department of Chemical Engineering and Chemistry

Eindhoven University of Technology

Het Kranenveld 14, P.O. Box 513, 5600 MB Eindhoven, The

Netherlands

Supporting Information can be found in the attached PDF document. cell designs. ${ }^{[8-10]}$ Indeed, gas-fed devices have demonstrated high geometric-area-specific current densities with a variety of carbon monoxide (CO) and hydrocarbon-selective metal electrocatalysts. ${ }^{[10-15]}$ However, most emerging gas-fed $\mathrm{CO}_{2}$ electrolyzers often exhibit limited durability, with performance decay after only a few hours of operation, ${ }^{[16,17]}$ in part because these cell formats employ GDEs based on repurposed polymer electrolyte fuel cell (PEFC) materials that are not tailored to electrolysis applications.

Gas diffusion layers (GDLs) in PEFCs are responsible for facilitating gas, liquid, electron, and heat transport in the presence of the reactant gases and water, so material composition and microstructures have been optimized accordingly. For example, removing water from the cathode $\mathrm{CL}$ is crucial to device operation, especially at high currents when generated liquid water inhibits oxygen flux. To this end, densely-packed partially-hydrophobized microporous layers (MPLs) coated onto carbon-fiber substrates (CFSs) serve both as high-surface-area, electronically-conductive contacts to the $\mathrm{CL}$ and as effective media for water management. ${ }^{[18-20]}$ Studies focused on water transport in PEFCs, enhanced by advanced operando imaging techniques, have motivated engineering both GDL microstructure and surface chemistry to achieve high power operation under water-saturated conditions. ${ }^{[21-28]}$

Recently, the need to understand electrolyte wetting phenomena at the gas-liquid interface within the GDE has been identified as an important area of investigation towards improving electrode durability for $\mathrm{CO}_{2}$ reduction. ${ }^{[29]}$ While PEFC GDLs embody desirable properties for $\mathrm{CO}_{2}$ electrolyzers (e.g., geometry, permeability, electrical conductivity), these materials are not designed to meet all requirements for device longevity (e.g., resistance to liquid electrolyte percolation, stability in alkaline $\mathrm{pH}$, durability under deeply cathodic potentials). Specifically, the efficacy of the MPL as a barrier to liquid electrolyte permeation, as is the case in liquid-electrolyte-based $\mathrm{CO}_{2}$ electrolyzers, is limited by increasing apparent hydrophilicity over time. ${ }^{[12]}$ Often, hydrophobicity/-philicity is measured via sessile drop contact angles $(\theta)$ between a surface (e.g., graphite) and a test fluid (e.g., water). High contact angles $\left(\theta>90^{\circ}\right)$ are indicative of hydrophobicity, whereas low contact angles $\left(\theta<90^{\circ}\right)$ describe hydrophilicity. Because water can exhibit a range of solid-liquid contact angles, $65^{\circ}<\theta<95^{\circ}$, across an assortment of graphitic and carbon-fiber surfaces, ${ }^{[30-33]}$ wet-proofing material, e.g. polytetrafluoroethylene (PTFE), is coated onto the carbon components to ensure that GDLs are hydrophobic. ${ }^{[33,34]}$ Translating this concept to alkaline $\mathrm{CO}_{2}$ electrolysis, a previous study by Kim et al. showed that tuning MPL PTFE loading to control electrolyte wetting improved $\mathrm{CO}$ selectivity over the parasitic hydrogen $\left(\mathrm{H}_{2}\right)$ evolution reaction $(\mathrm{HER}){ }^{\left[{ }^{35]}\right.}$ Although this 


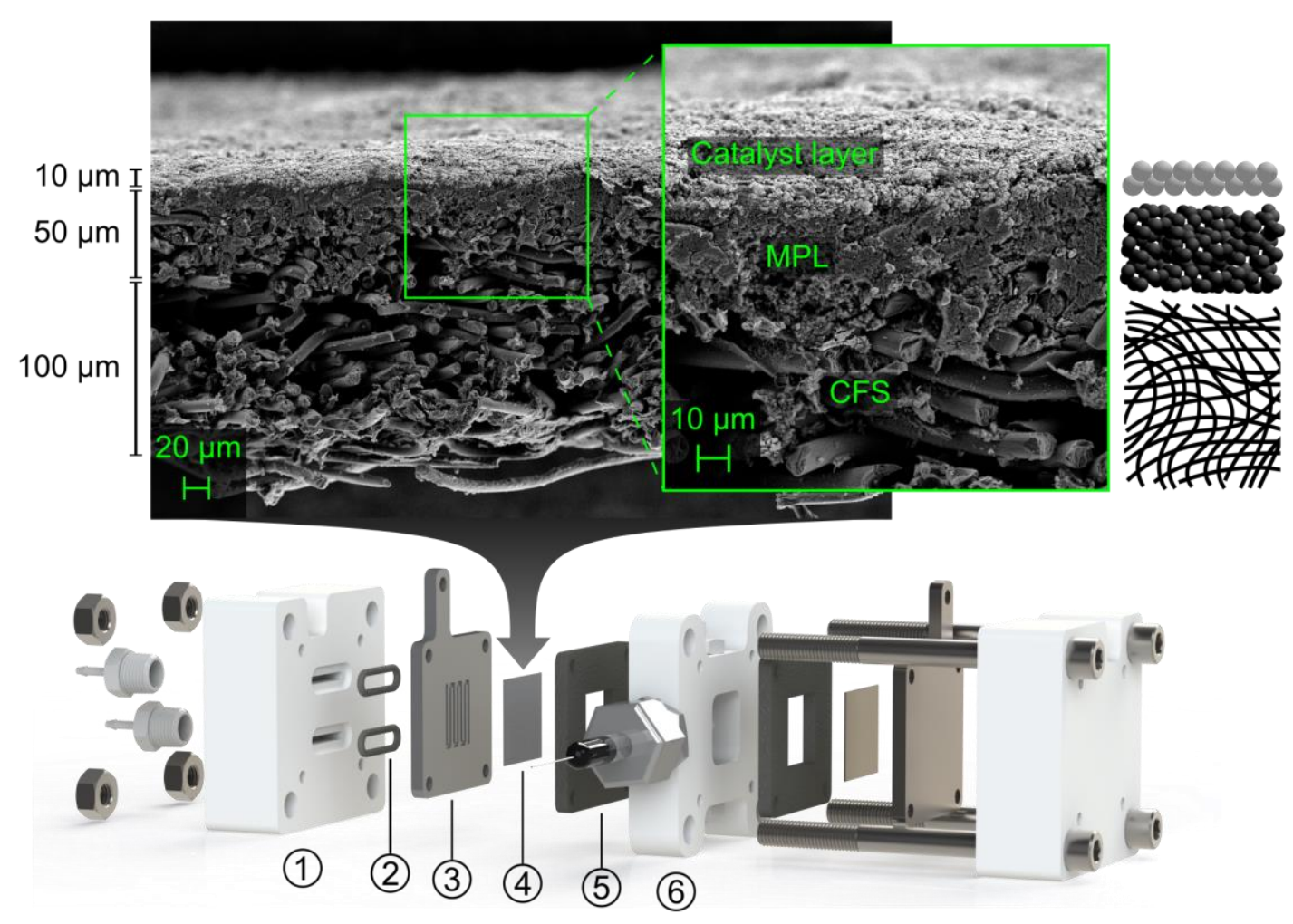

Figure 1. Gas diffusion electrodes (top, Freudenberg H23C6) with a silver (Ag) catalyst layer (CL), a microporous layer (MPL), and a carbon fiber substrate (CFS) are loaded into a custom-built gas-fed, flowing-electrolyte electrolyzer (bottom) with a $\mathrm{Hg} / \mathrm{HgO}$ reference electrode. An exploded view of the cell shows the (1) diffuser plates, (2) O-ring gaskets, (3) current collectors/flow fields, (4) gas diffusion electrode (cathode)/metal electrode (anode), (5) planar gaskets, (6) and electrolyte flow channel with reference electrode.

work demonstrated promising $\mathrm{CO}_{2}$ reduction activity with Agcoated GDEs (Ag-GDEs), the short runs typical of catalyst screening experiments (i.e., several minutes to an hour) may not allow enough time for the detrimental effects of electrode flooding to become apparent. Longer-term operation in the gas-fed, flowing electrolyte format is sometimes explored, but stable performance remains elusive. In these cases, electrode flooding along with a changeover from $\mathrm{CO}$ to $\mathrm{H}_{2}$ in the product gas stream are consistently reported. ${ }^{[11,16]}$

Pursuant to the goal of better understanding the dynamics of GDE flooding in a flowing electrolyte $\mathrm{CO}_{2}$ electrolyzer, we conducted a systematic study of electrode stability across a range of current densities in an alkaline electrolyte. In addition to voltage-current and product composition measurements, we quantify the electrochemical double-layer capacitance (EDLC) to track electrolyte ingress into the GDE during electrolysis. We hypothesized that EDLC, proportional to wetted electrode area, is inversely correlated with cell performance and that measurable deviations from the desired steady state, specifically the transition from $\mathrm{CO}$ to $\mathrm{H}_{2}$ production, may be captured by this metric. Recently, EDLC measurements have been used to quantify the wetted surface area of macroporous, fibrous carbon GDLs when subjected to a range of capillary pressures with electrolyte on one side and air at ambient conditions on the other. ${ }^{[36]}$ While direct measurement of wetted surface areas is desirable, it is best suited for homogenous materials with a defined specific capacitance (in units of F/unit area) extracted from a representative sample of a known geometric area and minimal roughness. In contrast, catalyst-coated GDEs are composite materials with regions of distinct surface chemistry that preclude quantitative deconvolution through a single EDLC measurement. ${ }^{[37]}$ Despite this constraint, meaningful performance comparisons can still be made between consistently prepared electrodes. Accordingly, EDLC measurements are a powerful technique for tracking electrolyte penetration for $\mathrm{CO}_{2}$ electrolyzers and other electrochemical devices that rely on stable gas-liquid interfaces (e.g., metal-air batteries, water electrolyzers, chlor-alkali electrolyzers).

\section{Results and Discussion}

\section{$\mathrm{CO}_{2}$ Electrolysis and Capacitance Measurements}

We employed the electrochemical reduction of $\mathrm{CO}_{2}$ to $\mathrm{CO}$ on silver $(\mathrm{Ag})$ as a model reaction due to its high selectivity, gaseous reactants/products, and robustness across multiple catalysts and cell configurations. . $^{[3,13,15,38-42]}$ We evaluated catalyst-coated Freudenberg GDLs in a custom-built, gas-fed electrolyzer with a flowing electrolyte (Figure 1). GDLs with MPLs (Freudenberg $\mathrm{H} 23 \mathrm{C} 6)$ were airbrush coated with an ink containing $\mathrm{Ag}$ nanoparticles $\left(\sim 0.5 \mathrm{mg} \cdot \mathrm{cm}^{-2}\right.$ geo $)$ and an alkaline ionomer from Dioxide Materials $^{\mathrm{TM}}$ to create GDEs with an active area of 2.55 $\mathrm{cm}^{2}$ geo as shown in the representative scanning electron 
microscopy (SEM) cross-section in Figure 1 (top). Freudenberg GDLs were selected for their mechanical flexibility and relatively defect-free MPL, ${ }^{[43]}$ which we anticipated may improve the flooding tolerance of the cathode. Additional SEM images of the GDE components (CFS, MPL, CL) are provided in the Supporting Information (Figure S1).

For all experiments, Ag-GDE cathodes were loaded into the cell shown in Figure 1 (bottom) along with a metallic nickel $(\mathrm{Ni})$ anode and a mercury/mercury oxide $(\mathrm{Hg} / \mathrm{HgO})$ reference electrode to enable independent measurement of individual electrode polarizations. The cell geometry was originally developed by our group as a small-scale redox flow battery testing platform ${ }^{[44]}$ and was recently adapted for a catalytic study of tin and tin oxide GDEs for electroreduction of $\mathrm{CO}_{2}$ to formate in a gas-fed, flowing alkaline electrolyte configuration. ${ }^{[45]}$ In this study, the cathode side was outfitted with a serpentine flow field machined from polymer-impregnated graphite and operated in gas-phase delivery mode. The serpentine flow field both provides electrical contact to the GDE and facilitates liquid removal by flowing gas, which allows experiments to continue until the advanced stages of electrode flooding. The anode side is outfitted with a titanium (Ti) current collector that is stable at the highly oxidizing potentials required for the oxygen $\left(\mathrm{O}_{2}\right)$ evolution reaction (OER). Evolved $\mathrm{O}_{2}$ gas and unrecovered cathode gas bubbles are removed from the cell by the flowing electrolyte stream and vented to atmosphere. The cell assembly protocol (Section S1), a schematic (Figure S2) and images (Figure S3) of the experimental setup, and a description of electrolyzer startup (Section S2) are provided in the Supporting Information.

Pure $(99.999 \%) \mathrm{CO}_{2}$ was fed at $20 \mathrm{sccm}$ to the CFSside of the Ag-GDE. An alkaline potassium hydroxide electrolyte $(\mathrm{KOH}, \mathrm{pH}=13.6)$ was chosen instead of a neutral to mildly alkaline $\mathrm{pH}$ potassium carbonate $\left(\mathrm{K}_{2} \mathrm{CO}_{3}\right) /$ bicarbonate $\left(\mathrm{KHCO}_{3}\right)$ electrolyte to minimize solution resistance across the full cell. ${ }^{[6]}$ Higher $\mathrm{pH}$ also enables lower overpotentials for converting $\mathrm{CO}_{2}$ to $\mathrm{CO}$ and/or hydrocarbons. ${ }^{[13,46]}$ To control the effects of carbonation, which consumes up to $5 \%$ of the feed $\mathrm{CO}_{2}$ at open circuit voltage (OCV) (Figure S4), the electrolyte stream was not recirculated but rather was passed once through the cell at $1 \mathrm{~mL} \cdot \mathrm{min}^{-1}$. These operating conditions mirror those commonly reported in the field and, therefore, illuminate the challenges of GDE durability in presentday flowing alkaline electrolyte configurations. ${ }^{12,13,35,38,47-50]}$

Each experiment was divided into 15-minute segments that are composed of a high-frequency resistance measurement $(10 \mathrm{~s})$ to determine solution resistance between the cathode and the $\mathrm{Hg} / \mathrm{HgO}$ reference electrode, a series of voltammetric sweeps between -100 and $+50 \mathrm{mV}$ vs $\mathrm{Hg} / \mathrm{HgO}$ to estimate cathode EDLC (50 s total), and, finally, a galvanostatic hold (14 min $15 \mathrm{~s}$ ). At the end of every time segment, the effluent gas from the cathode halfcell was sampled by a gas chromatography (GC) system. The effluent electrolyte was not analyzed for the presence of liquid- phase products because $\mathrm{Ag}$ electrocatalysts are anticipated to generate primarily gaseous $\mathrm{CO}$ and $\mathrm{H}_{2}$ at the conditions tested..$^{[2,3]}$

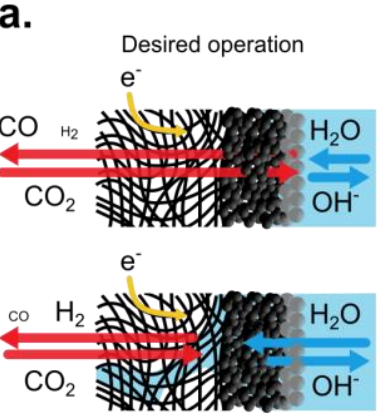

Flooded operation

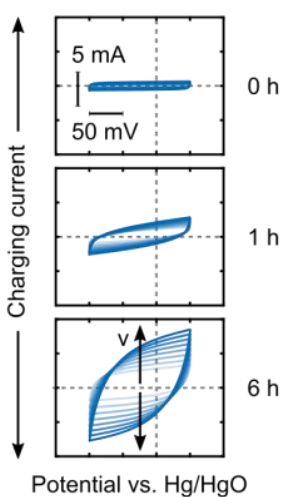

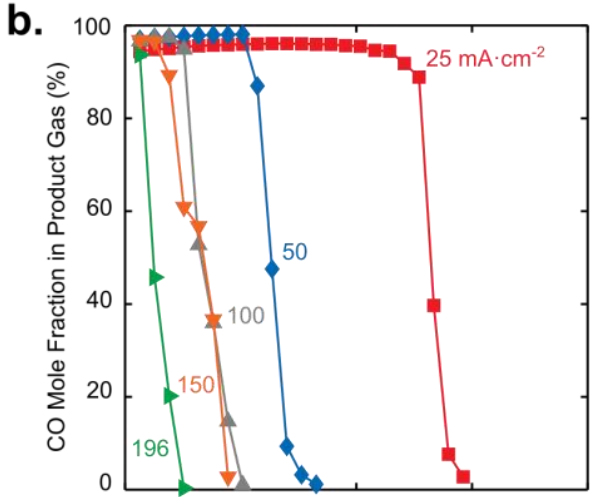

d.

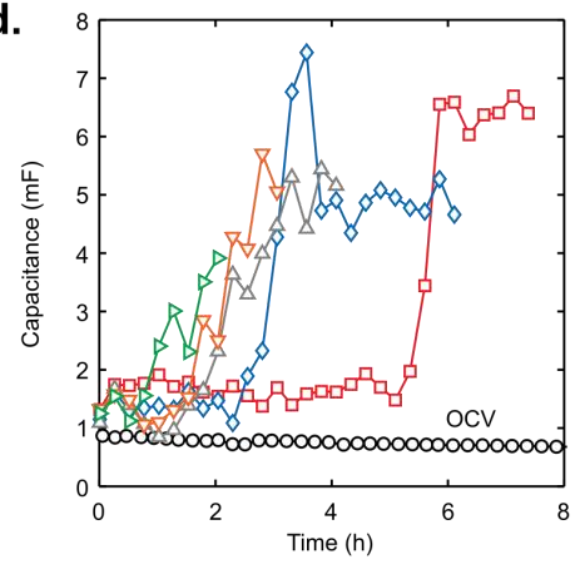

Figure 2. (a) GDE flooding limits $\mathrm{CO}_{2}$ flux to the catalyst layer and promotes HER. (b) ncreasing current densities $\left(\mathrm{mA} \cdot \mathrm{cm}^{-2}\right)$ applied to Ag-GDEs are associated with a decreasing urrents extracted from cyclic voltammetry every $15 \mathrm{~min}$ increase (d) Sudden catastrophic in CO production qualitatively correlate inversely with sharp increases in capacitance densities.

Constant current electrolysis, i.e., galvanostatic, experiments were run to probe the effect of current density on $\mathrm{CO}$ mole fraction in the effluent gas over time. An advantage of galvanostatic operation, as compared to potentiostatic operation, is that the total product gas generation rate should remain constant because both reaction products, $\mathrm{CO}$ and $\mathrm{H}_{2}$, require 2 moles of electrons per mole of product as shown in the following half-reaction equations (Section S3),

$$
\begin{aligned}
& \mathrm{CO}_{2}(\mathrm{aq})+\mathrm{H}_{2} \mathrm{O}(\mathrm{l})+2 \mathrm{e}^{-} \rightarrow \mathrm{CO}(\mathrm{g})+2 \mathrm{OH}^{-}(\mathrm{aq}) \\
& \left(\mathrm{E}^{0}=-0.10 \mathrm{~V} \text { vs } \mathrm{RHE}\right) \\
& 2 \mathrm{H}_{2} \mathrm{O}(\mathrm{l})+2 \mathrm{e}^{-} \rightarrow \mathrm{H}_{2}(\mathrm{~g})+2 \mathrm{OH}^{-}(\mathrm{aq})\left(\mathrm{E}^{0}=0.00 \mathrm{~V} \text { vs } \mathrm{RHE}\right)
\end{aligned}
$$

The graphical representation of gas-fed $\mathrm{CO}_{2}$ electrolysis shown in Figure 2a depicts both desired and flooded operational states within a Ag-GDE. As described earlier, nominally hydrophobic GDLs are used to limit electrolyte intrusion into the gas stream, while maintaining $\mathrm{CO}_{2}$ flux. However, once electrolyte floods the GDE the liquid diffusion length for $\mathrm{CO}_{2}$ to the $\mathrm{CL}$ increases to the point that the $\mathrm{CO}_{2}$ flux cannot support the current demand for $\mathrm{CO}$ 
production and HER becomes favored throughout the wetted portions of the electrode.

The evolution of electrode performance as a function of time across a series of current densities $(25,50,100,150$, and 196 $\mathrm{mA} \cdot \mathrm{cm}^{-2}$ ) is shown in Figure $2 \mathrm{~b}$. Across all current densities tested the peak CO mole fraction was $>90 \%$, which agrees with performance from previous reports using Ag-catalyzed GDEs. ${ }^{[13,51]}$ After the first 15 min of operation, notable differences emerge when applying different current densities. For low to moderate current densities there is a period of steady $\mathrm{CO}$ production, ranging from $1-5 \mathrm{~h}$ and inversely dependent on the magnitude of the applied current density, followed by a catastrophic failure evinced by a rapid decrease in the $\mathrm{CO}$ product mole fraction, while for the higher current densities of 150 and 196 $\mathrm{mA} \cdot \mathrm{cm}^{-2}$, the electrode transitions from $\mathrm{CO}$ to $\mathrm{H}_{2}$ production within $30 \mathrm{~min}$ of operation. The cathode potential grows more negative during stable operation but becomes more positive as the dominant product transitions $\mathrm{CO}$ to $\mathrm{H}_{2}$ (Figure S5) and more of the GDE carbon becomes wetted by electrolyte. As the accessible area for HER increases, the cathode potential is anticipated to decrease in magnitude. The HFR traces do not show a clear trend among the current densities tested (Figure S6).

EDLC (hereafter referred to as capacitance) measurements provide additional insight into the cathode state as the product gas mole fraction transitions from $\mathrm{CO}$ - to $\mathrm{H}_{2}$-rich. As shown in Figure 2c, we observe that the currents from cyclic voltammetry increase over time, indicating changes at the electrode-electrolyte interface. After extracting and processing the capacitive currents at each time point, we plot the capacitance as a function of time (Figure 2d). We find that when we hold the cell at OCV for at least $8 \mathrm{~h}$ as a zero-current baseline and observe relatively steady capacitance between $0.5-1.0 \mathrm{mF}$ over time, indicating that the electrode-electrolyte interface is stable before electrolysis begins. After passing faradaic current through the cell for $15 \mathrm{~min}$, the capacitance increased to $1.5-2.0 \mathrm{mF}$ for all current densities. Similar to the product composition traces in Figure $2 \mathrm{~b}$, we observe steady capacitance for low to moderate current densities until a sudden increase that coincides with performance failure.

In general, we observe a qualitatively inverse correlation between $\mathrm{CO}$ mole fraction in the product gas and cathode capacitance (Figure S7). We also see that changes in capacitance lag behind changes in $\mathrm{CO}$ mole fraction by at least $15 \mathrm{~min}$. This delay coupled with the observation that the capacitance subtly decreases prior to each catastrophic flooding event suggests that liquid electrolyte penetration into the GDE may not be the sole cause of performance failure.

From the collection of traces in Figures $2 b$ and $d$, we see that the rate of GDE failure is positively correlated with increasing current. Exploring the possibility that faradaic processes influence the time to failure, we plot $\mathrm{CO}$ mole fraction (Figure 3a) and capacitance (Figure $3 b$ ) as a function of the cumulative charge passed $(Q)$ in Figure 3, where $Q=I \times t, l$ is absolute current $(\mathrm{mA})$, and $t$ is time passed (h). While reporting electrochemical data as a function of charge passed (units of mAh), as opposed to time, is more commonly associated with energy storage devices, in the present context, quantifying charge passed until failure may provide insight into the "capacity" of the GDE. Interestingly, we observe a collapse of the $\mathrm{CO}$ mole fraction data onto a single sigmoidal curve (Figure 3a), with especially good agreement at low charges (ca. 0 - $400 \mathrm{mAh}$ ), suggesting that currentdependent changes to the electrolyte (e.g., increased cathode alkalinity leading to accelerated carbonation), may influence the rate of flooding. Furthermore, the capacitance data (Figure 3b) reveals a similar onset charge to flooding across experiments, although there is scatter at higher charges (> $400 \mathrm{mAh}$ ) after the onset of product changeover. The capacitance data, plotted either as a function of time (Figure 2d) or charge (Figure 3b), do not appear to approach a consistent maximum value at the advanced stages of electrode failure. We reason that flooding pathways are stochastic in both the MPL and CFS and that the extent of observable GDE saturation resulting from electrolyte permeation throughout the CFS varies due to microstructural differences between individual electrodes. Enlarged plots of the Figures $3 a$ and $b$ data from $0-500 \mathrm{mAh}$ (Figure S8) along with a description of the sigmoid function used for qualitatively fitting each data set are provided in the Supporting Information.

The chemical and physical mechanisms that underlie these trends are not yet fully understood and, to our knowledge, have neither been extensively reported nor discussed in the context of gas-fed $\mathrm{CO}_{2}$ electrolyzers. Although GDE flooding may be caused by a variety of phenomena (e.g., macroscopic pressure imbalances, evolutions in surface wettability, evaporationcondensation), for this study, we focus on the connections between carbonation and flooding since we consistently observe salt crystallites on the backside of flooded GDEs and at the inlet of the cathode flow field (Figure S9). Specifically, we postulate that the transition from $\mathrm{CO}$ to $\mathrm{H}_{2}$ production within GDEs is driven by phenomena that occur in parallel with electrolysis but manifest and negatively impact performance at different rates.

The first phenomenon is electrolyte carbonation, which occurs wherever dissolved $\mathrm{CO}_{2}$ and hydroxide $\left(\mathrm{OH}^{-}\right)$ions co-exist. This effectively includes all electrolyte-wetted regions of the Ag-GDE. Indeed, such $\mathrm{CO}_{2}$ chemisorption is deliberately leveraged in direct air capture processes to selectively remove dilute $\mathrm{CO}_{2}$ from the atmosphere. ${ }^{[52]}$ First, $\mathrm{CO}_{2}$ reacts with one $\mathrm{OH}^{-}$to form a bicarbonate $\left(\mathrm{HCO}_{3}^{-}\right)$intermediate, then the newly formed $\mathrm{HCO}_{3}^{-}$ reacts with a second $\mathrm{OH}^{-}$to produce one carbonate $\left(\mathrm{CO}_{3}{ }^{2-}\right)$ and one water $\left(\mathrm{H}_{2} \mathrm{O}\right)$ molecule as shown by following chemical equations,

$\mathrm{CO}_{2}(\mathrm{aq})+\mathrm{OH}^{-}(\mathrm{aq}) \leftrightarrow \mathrm{HCO}_{3}^{-}(\mathrm{aq})$

$\mathrm{HCO}_{3}^{-}(\mathrm{aq})+\mathrm{OH}^{-}(\mathrm{aq}) \leftrightarrow \mathrm{CO}_{3}^{2-}(\mathrm{aq})+\mathrm{H}_{2} \mathrm{O}(\mathrm{I})$

A kinetic study reported by Schulz et al. shows that the forward rate for Equation 4 is faster than that for Equation 3, so most $\mathrm{CO}_{2}$ that reacts with the $\mathrm{OH}^{-}$-rich electrolyte is effectively converted to $\mathrm{CO}_{3}{ }^{2-}{ }^{[53]}$ We see that this parasitic loss is initially overcome to sustain high selectivity for $\mathrm{CO}$ production, likely because $\mathrm{CO}_{2}$ is fed in stoichiometric excess. However, carbonation of the electrolyte not only increases single-pass conversion to the undesired products of $\mathrm{HCO}_{3}{ }^{-}$and $\mathrm{CO}_{3}{ }^{2-}$, but also indirectly slows $\mathrm{CO}_{2}$ reduction kinetics by initiating an unfavorable shift towards more neutral $\mathrm{pH} .{ }^{[48]}$ Furthermore, galvanostatic operation ensures that HER, which also produces $\mathrm{OH}^{-}$ions (Equation 2), will substitute for any lost $\mathrm{CO}_{2}$ reduction within the $\mathrm{CL}$. Therefore, as the rate of $\mathrm{CO}_{2}$ electrolysis decreases, the persistently high local 


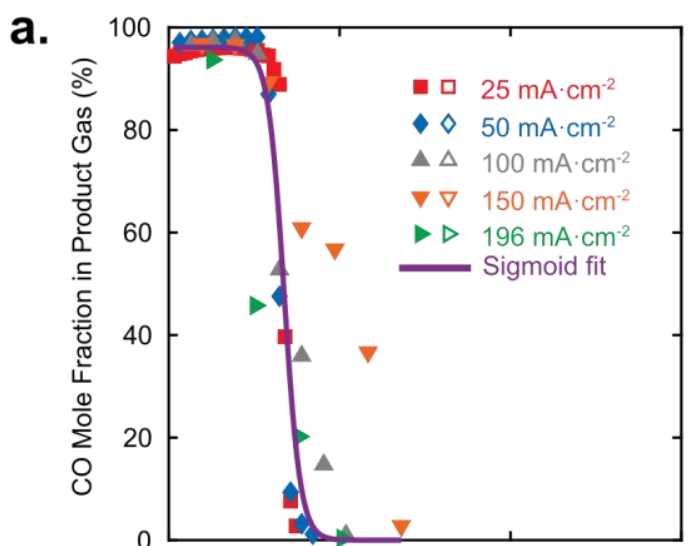

b.

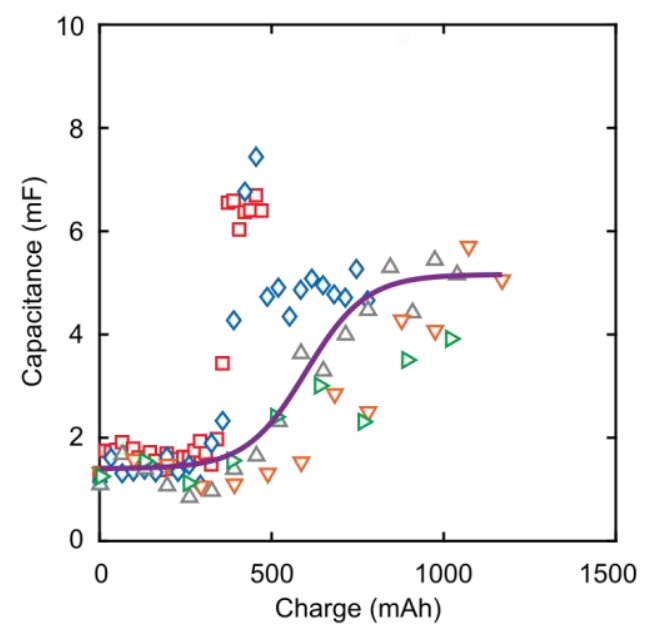

Figure 3. Plotting (a) $\mathrm{CO}$ mole fraction in the product gas (\%) and (b) capacitance $(\mathrm{mF})$ as functions of cumulative charge $(\mathrm{mAh})$ results in some collapse of the performance data. This indicates that faradaic processes, i.e. $\mathrm{CO}_{2}$ reduction and $\mathrm{HER}$, likely contribute to the onset of GDE failure.

$\mathrm{pH}$ due to $\mathrm{HER}$ in the presence of any excess $\mathrm{CO}_{2}$ will accelerate the carbonation rate in a positive feedback loop. This performance drift is mirrored by negative/cathodic drift in the electrode potential trace that emerges before the onset of catastrophic flooding (Figure S5). When operating galvanostatically, such increases to the cathode potential can be attributed to some combination of increased kinetic overpotential due to local electrolyte neutralization and increased $\mathrm{CO}_{2}$ mass transport resistance as liquid blocks gas diffusion pathways.

The second phenomenon is the emergence of physical blockages within the GDE that inhibit $\mathrm{CO}_{2}$ flux and promote HER. Both solid (i.e., salt crystallites) and liquid (i.e., electrolyte) species emerge on the gas side of the cathode flow field (Figure S9) once liquid electrolyte breaks through the GDE. After partially filling the CFS, liquid electrolyte is trapped until sufficient convection is applied to physically displace the droplets or until the water evaporates leaving behind salt crystals that hinder gas flux to the CL. ${ }^{[54]}$ As the pure $\mathrm{CO}_{2}$ feed contacts the electrolyte, carbonation together with water evaporation synergistically increase the likelihood of precipitation because $\mathrm{KHCO}_{3}$ (3.62 $\left.\mathrm{mol} / \mathrm{kg} \mathrm{H}_{2} \mathrm{O}\right)$ and $\mathrm{K}_{2} \mathrm{CO}_{3}\left(8.03 \mathrm{~mol} / \mathrm{kg} \mathrm{H}_{2} \mathrm{O}\right.$ ) have lower solubilities than $\mathrm{KOH}\left(21.57 \mathrm{~mol} / \mathrm{kg} \mathrm{H}_{2} \mathrm{O}\right)$ on a molal basis. ${ }^{[6]}$ Furthermore, both hydrated and dehydrated alkali carbonates in the solid phase (e.g., $\mathrm{K}_{2} \mathrm{CO}_{3}$ ) can also consume additional $\mathrm{CO}_{2}$ to produce bicarbonates (e.g., $\mathrm{KHCO}_{3}$ ) per the following equations, ${ }^{[55]}$

$\mathrm{K}_{2} \mathrm{CO}_{3} \cdot 1.5 \mathrm{H}_{2} \mathrm{O}(\mathrm{s})+\mathrm{CO}_{2}(\mathrm{~g}) \leftrightarrow 2 \mathrm{KHCO}_{3}(\mathrm{~s})+0.5 \mathrm{H}_{2} \mathrm{O}(\mathrm{g})$

$\mathrm{K}_{2} \mathrm{CO}_{3}(\mathrm{~s})+\mathrm{CO}_{2}(\mathrm{~g})+\mathrm{H}_{2} \mathrm{O}(\mathrm{g}) \leftrightarrow 2 \mathrm{KHCO}_{3}(\mathrm{~s})$

As our ability to measure species concentrations at relevant length scales $(\sim \mu \mathrm{m})$ within GDEs is limited, precise accounting of chemical and electrochemical reaction dynamics is difficult to achieve experimentally. Nonetheless, due to the mass action reflected by Equations 1-6 we anticipate that complex dynamic equilibria between ionic species emerge near the $\mathrm{CO}_{2}$-electrolyte interface during electrolysis, depending on the operating conditions and the movement of species within the electrode microstructure.

The collapse of the performance data when plotted as a function of cumulative charge (Figure 3 ) suggests that the electrode has a charge threshold that, if exceeded, will lead to failure. Charge directly translates to newly formed $\mathrm{OH}^{-}$ions that become available for carbonation reactions (Equations 3 and 4) near the gas-liquid interface of the GDE. By considering the electrolysis data in Figures 2 and 3 together with the stoichiometry of Equations 1-4, we can infer that carbonation rate at the cathode increases with current density. Indeed, electrochemically-mediated $\mathrm{CO}_{2}$ separation schema leveraging this phenomenon have been proposed. ${ }^{56-58]}$ Accordingly, we hypothesize that GDE failure is initiated by carbonate salt precipitation followed by rapid electrolyte percolation through the crystallites which retards $\mathrm{CO}_{2}$ transport sufficiently as to necessitate $\mathrm{H}_{2}$ generation via water splitting to meet imposed galvanostatic requirements. A similar electrode degradation mechanism has previously been proposed for air-fed, flowing electrolyte alkaline fuel cells.[59] This hypothesis is further supported by results from fundamental porous media evaporation studies, which show that once salt crystallites effloresce at the MPL-CFS interface, they can pump water through the MPL via capillary action due to their hygroscopic character. ${ }^{[60]}$

Managing the parasitic capture of $\mathrm{CO}_{2}$ by aqueous electrolytes and the precipitation of carbonate salts, thereafter, may benefit from electrode-level models that can predict precipitation events in response to selected operating conditions such as the ionic strength of the electrolyte, the bulk electrolyte $\mathrm{pH}$, the $\mathrm{pH}$ of the electrode-electrolyte interface, and the water vapor content in the feed gas. ${ }^{[61]}$ Given the diversity of porous media available, the characteristic behavior for the Freudenberg GDLs presented here may not be representative of or predictive for all GDEs, but the underlying chemical and physical phenomena associated with $\mathrm{CO}_{2}$ electrolysis, $\mathrm{OH}^{-}$generation, and carbonation are expected to persist for all electrodes and for all mild to strong alkaline aqueous electrolytes used in a gas-fed, flowing electrolyte configuration. For the remainder of this work, we seek to validate the proposed carbonate-driven flooding mechanism and to explore the possibility of restoring electrode functionality after failure.

Capillary Pressure Breakthrough Measurements 
To explore the extent to which the magnitude of the faradaic current impacts the severity of electrode failure, we characterized the post-test ex situ flooding resilience of Ag-GDEs used in the electrolysis experiments. We employed capillary pressure imbibition with deionized water to quantify and map the apparent loss of hydrophobicity of Ag-GDE samples. Water is an appropriate test liquid for these experiments because the $\mathrm{KOH}$ solution used in the electrolysis experiments (ca. $5 \mathrm{wt} \%$ ) has similar density $\left(1.05 \mathrm{~g} \cdot \mathrm{cm}^{-3}\right)$ and surface tension $\left(0.075 \mathrm{~N} \cdot \mathrm{m}^{-1}\right)$ to water $\left(0.99 \mathrm{~g} \cdot \mathrm{cm}^{-3}, 0.073 \mathrm{~N} \cdot \mathrm{m}^{-1}\right)$ at room temperature $\left(20^{\circ} \mathrm{C}\right){ }^{[62]}$ Capillary pressure imbibition is a method by which gas-liquid pressure differences $\left(P_{\mathrm{L}}-P_{\mathrm{G}}\right)$ are applied across a porous material to induce intrusion or withdrawal of liquid. It has been utilized extensively to characterize the wettability/saturation characteristics of PEFC cathode GDLs. ${ }^{[63-66]}$ In the $\mathrm{CO}_{2}$ electrolysis field, carbon-based GDLs with MPLs adopted from PEFCs have been understood to be macroscopically hydrophobic and, therefore, are considered suitable candidates for catalyst scaffolds and gas-liquid barriers. ${ }^{[6]}$ However, because carbonate salts are hygroscopic, any embedded crystallites left behind after electrolyte flooding events would decrease the resilience of the electrode to liquid intrusion.

To quantify the possible effects of electrolysis on apparent electrode hydrophobicity, we measure the breakthrough pressure of water through GDLs and GDEs with the MPL (if applicable) facing the water in a custom-designed apparatus (Figure S10) inspired by analogous setups in the literature. ${ }^{[54,65,68,69]}$ First, circular samples of pristine carbon-paper GDLs with (Freudenberg H23C6) or without (Freudenberg H23) MPLs were screened as comparisons for the Ag-GDE samples. As reported in the two leftmost data in Figure 4a, the average breakthrough pressure $(\mathrm{N}=5)$ for the CFS (Figure $\mathrm{S} 1 \mathrm{a})$ is (23 mbar). After adding an MPL (Figure S1b) to the CFS, the average breakthrough pressure $(\mathrm{N}=5)$ increases by an order of magnitude (642 mbar). Next, the same Ag-GDEs used for the experiments reported in Figure 2, were screened post-test. Prior to imbibition, Ag-GDE samples were removed from the electrolysis cell, thoroughly rinsed with deionized water to remove any surface salts and excess electrolyte, and then left to dry in ambient laboratory air. For these electrodes we expect the breakthrough pressures to decrease in the base case due to the application of a $\mathrm{Ag} \mathrm{CL}$ that includes hydrophilic ionomer (Figure S1c), which may seep into the MPL during airbrush deposition (Figure S11). ${ }^{[70]}$ The low surface tension of organic-aqueous mixtures that constitute the carrier solvents for catalyst inks may be responsible for the formation of hydrophilic regions within the GDE near the CL-MPL interface. However, embedded crystallites are anticipated to have a more drastic effect on flooding resilience (vide supra). Indeed, the breakthrough pressures for these samples ( $\mathrm{N}=2$ for OCV , 25, 100, 150, $196 \mathrm{~mA} \cdot \mathrm{cm}^{-2}$ and $\mathrm{N}=1$ for $50 \mathrm{~mA} \cdot \mathrm{cm}^{-2}$ ) decrease to less than $100 \mathrm{mbar}$, except for the 25 $\mathrm{mA} \cdot \mathrm{cm}^{-2}$ samples, which retain more of the breakthrough resistance. The $196 \mathrm{~mA} \cdot \mathrm{cm}^{-2}$ samples exhibit the lowest average breakthrough pressure (22 mbar), which is equivalent to that of the CFS in isolation (23 mbar). The samples held at OCV retain an average breakthrough pressure (446 mbar) that is closer to a pristine GDL with MPL than to any of the post-run samples, a.

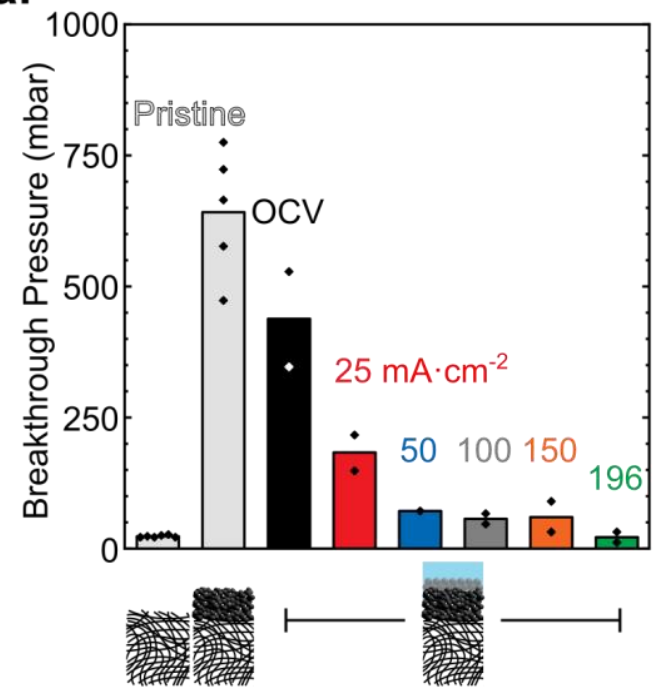

b.

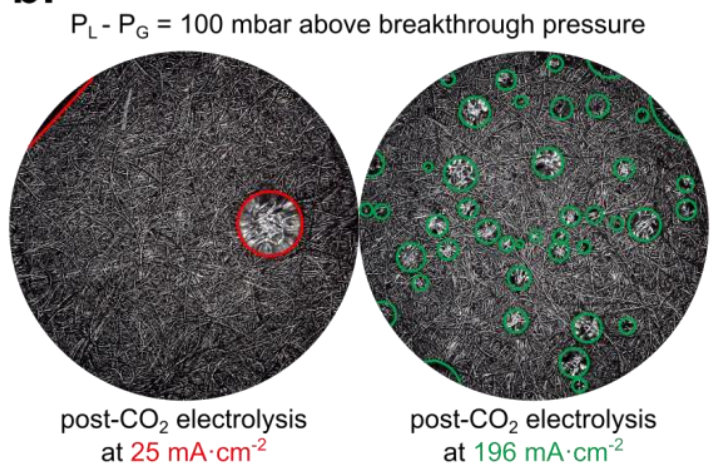

Figure 4. (a) Breakthrough pressures for Ag-GDEs decrease with increasing current density (25-196 $\mathrm{mA} \mathrm{cm}^{-2}$ ) and approach the value for the bare CFS (H23), while the Ag-GDE held at OCV retains breakthrough resistance that is closer to the value for uncoated GDL with an MPL (H23C6). (b) Representative images of the CFS while applying a capillary pressure 100 mbar in excess of the breakthrough point to the MPL side of Ag-GDEs demonstrate the greater extent of liquid percolation for Ag-GDEs after operation at disparate current densities.

suggesting that immersing GDEs in electrolyte without passing faradaic current may not compromise the hydrophobicity, at least not at these experimental timescales.

The lower breakthrough pressures for used GDE samples could be explained by either irreversible mechanisms, such as chemical degradation of PTFE, or reversible mechanisms, such as efflorescent salt deposits within the GDL. Although PTFE degradation has been reported under cathodic potentials in aqueous electrolyte, ${ }^{[71]}$ additional spectroscopic, microscopic, and chemical analyses may be required in the future to evaluate the extent to which this failure mode impacts performance. Strengthening the hypothesis of carbonation-accelerated electrode failure, is the observation of well-distributed liquid breakthrough points on the CFS that likely correspond to the locations of salt deposits left behind by electrolyte flooding and carbonate precipitation. Representative CFS images under positive capillary-pressure conditions are shown in Figure $4 \mathrm{~b}$. 
Although we observe a diminishing resilience to the initial liquid breakthrough with increasing current density, water eventually percolates through multiple points simultaneously at sufficiently high capillary pressures across all samples. The carbonate-driven flooding mechanism is quantitatively supported by the observation that flooding resistance of each sample generally decreases with increases in applied current density. This aligns with the notion that higher current density produces higher alkalinity and, therefore, increased carbonation within the wetted regions of an electrode (vide supra). Because we observe that water eventually percolates at multiple locations for all post-test samples, we can also infer that this failure mechanism is common to all Ag-GDEs used in this work.

We confirm the presence of crystallized salts in the pores of flooded GDEs by combining cross-sectional SEM images with elemental mapping of carbon $(C), A g$, fluorine $(F)$, potassium $(K)$, and oxygen (O). We see from maps of the pristine (Figure S12), post-test $25 \mathrm{~mA} \cdot \mathrm{cm}^{-2}$ (Figure S14), and post-test $196 \mathrm{~mA} \cdot \mathrm{cm}^{-2}$ (Figure S14) samples that the $\mathrm{K}$ signal conformally covers the MPL-regions of both flooded samples, but not the pristine sample. Discrete $\mathrm{K}$ nodules are visible for the $196 \mathrm{~mA} \cdot \mathrm{cm}^{-2}$ sample, but not for the $25 \mathrm{~mA} \cdot \mathrm{cm}^{-2}$ sample, suggesting that the carbonation rates, which vary with applied current density, impact the size, location, and likely growth dynamics of the salt deposits. Overall, we see from both imaging and ex situ breakthrough pressure measurements that the favorable barrier properties of the MPL are nullified by the presence of embedded salts left behind after electrolyte flooding. To complement the findings from this ex situ study, we sought to test our hypothesis of carbonation-driven flooding by probing the reversibility of electrode failure.

\section{Gas Diffusion Electrode Recovery}

Based on the results from both electrolysis (Figures 2 and 3 ) and breakthrough pressure (Figure 4) measurements, we explored the possibility of recovering electrode performance through either in situ OCV holds or ex situ electrode restoration. If periodic restoration is required, then in situ recovery facilitated by switching to OCV would be the more appealing operating strategy because it avoids cell disassembly.

First, we operated the cell galvanostatically at $50 \mathrm{~mA} \cdot \mathrm{cm}^{-2}$ for 1 $\mathrm{h}$ at the same conditions as the previous electrolysis experiments (Figure 2) before switching the cell to OCV for an extended hold. The peak CO mole fraction (Figure $5 \mathrm{a}$ ) remains over $95 \%$ during the initial 1-h galvanostatic period, confirming that substantial flooding has yet to occur. This is also supported by the capacitance trace, which shows that the GDE is stable during the initial hour and for the next $48 \mathrm{~h}$ while at OCV. During this extended hold, the gas outlet stream is not flooded with electrolyte, but some condensation is visible through the acrylic backing plate

a.

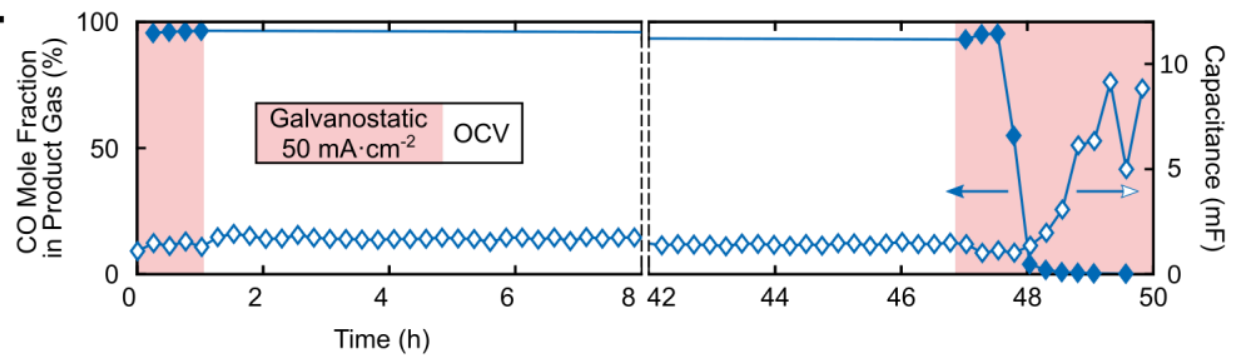

b.

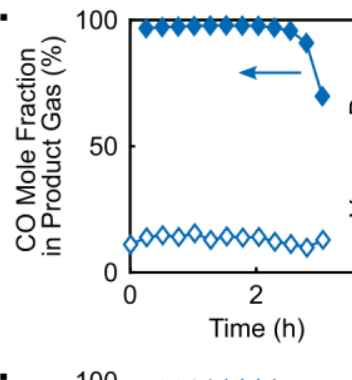

d.
C.

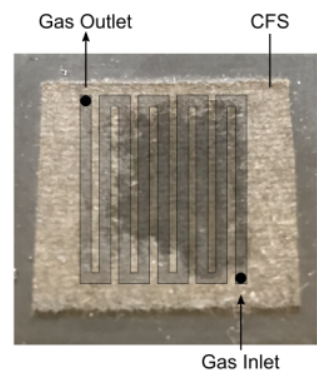

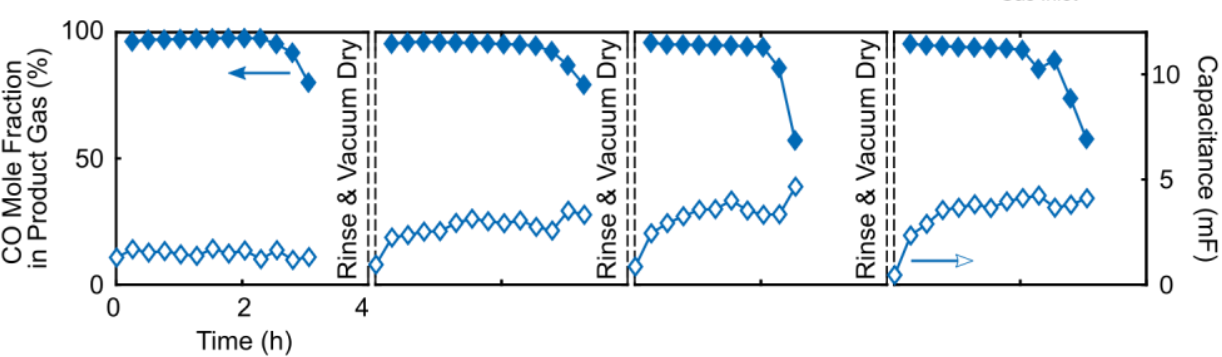

Figure 5. (a) Operating the cell at $50 \mathrm{~mA} \cdot \mathrm{cm}^{-2}$ for $1 \mathrm{~h}$ and then switching to OCV for $48 \mathrm{~h}$ results in nearly immediate performance failure after restoring current. This indicates that flooding may occur slowly at OCV but is likely accelerated by faradaic processes. (b) Drying a partially flooded GDE after operating at $50 \mathrm{~mA} \cdot \mathrm{cm}^{-2}$ does not restore the initial performance. (c) The portion of the GDE closest to the serpentine channel inlet, where $\mathrm{CO}_{2}$ concentration is highest and humidity is lowest, floods first as indicated by the darker portion of the CFS. (d) Rinsing partially flooded GDEs in DI water then drying restores much of the peak performance although it gradually decreases after repeated uses. 
near the gas outlet. The moisture may either come from evaporation of water in the electrolyte or from water liberated as a product of the $\mathrm{HCO}_{3}{ }^{-}$to $\mathrm{CO}_{3}{ }^{2-}$ reaction at the gas-electrolyte interface (Equation 4). Regardless of the source, if not managed appropriately, moisture buildup in the gas channel without the passage of current is anticipated to be problematic for electrolyzer longevity. After current is restored, the performance is only stable for ca. $30 \mathrm{~min}$ before catastrophic failure. The total time on stream before failure was ca. $2 \mathrm{~h}$ of galvanostatic operation when including a current pause, which is somewhat shorter than the uninterrupted experiment (Figure 2) that lasted around $2.5 \mathrm{~h}$. Even though there are no detectable changes to the cathode capacitance after $1 \mathrm{~h}$ of electrolysis, it appears that carbonation compromises the electrode performance even when the cell is held at OCV. Because carbonation persists in the absence of current, in situ restoration strategies like the one explored here may ultimately be ineffective.

Depending on the frequency of intervention, ex situ electrode rinses may be a viable approach for removing salt from porous electrodes. To this end, we tested if rinsing and/or drying GDEs could recover the same $\mathrm{CO}_{2}$ conversion performance as pristine ones. Previous works report rinsing GDEs after $\mathrm{CO}_{2}$ reduction to restore electrochemical activity, but the wetted state of the electrode during operation beyond the achievable current density and faradaic efficiency was not discussed. ${ }^{[16,72,73]}$ Continuing with the same electrolysis protocol, we started by running experiments at $50 \mathrm{~mA} \cdot \mathrm{cm}^{-2}$ until the onset of GDE failure, defined here as the inflection in the $\mathrm{CO}$ mole fraction trace. Next, we shut down the electrolyzer, removed the Ag-GDE, and either (1) dried or (2) rinsed and dried the electrode before reinstalling it in the cell. First we observe from the $\mathrm{CO}$ mole fraction and capacitance traces in Figure $5 b$ that vacuum drying alone results in GDE failure within 30 min of starting the subsequent run. After partial flooding we observe electrolyte measured to be ca. $\mathrm{pH} 10$, via a pH test strip $(0-14$ scale, VWR), on the CFS closest to the gas inlet of the serpentine flow field as indicated by the darker regions of a representative image (Figure $5 \mathrm{c}$ ). In this $\mathrm{pH}$ range, the electrolyte likely contains both $\mathrm{KHCO}_{3}$ and $\mathrm{K}_{2} \mathrm{CO}_{3} .{ }^{\left[{ }^{[3]}\right]}$ The liquid distribution on the CFS suggests a non-uniform permeation rate across the electrode area. Notably, flooding is concentrated where the $\mathrm{CO}_{2}$ concentration is the highest and the flowing gas humidity is lowest, which aligns with conditions that most strongly shift chemical and physical equilibria towards carbonation and precipitation of $\mathrm{K}_{2} \mathrm{CO}_{3} / \mathrm{KHCO}_{3}$ crystallites.

Next, we used the same electrolysis conditions but rinsed the GDE with deionized water after each run and prior to vacuum drying. As shown in Figure $5 \mathrm{~d}$ we observe that rinsing and drying a partially flooded GDE between each run restores much of the performance. However, the maximum $\mathrm{CO}$ mole fraction continually decreases, albeit by relatively minor amounts on subsequent runs, demonstrating that each rinse/dry cycle does not fully restore peak performance. These observations agree with a recent report by Endrödi et al. for a multi-cell $\mathrm{CO}_{2}$ electrolyzer stack study in which they injected water into cathode gas stream to wash away $\mathrm{K}_{2} \mathrm{CO}_{3}$ precipitates that block $\mathrm{CO}_{2}$ flux and they observed that peak current density decreased over time at a fixed voltage. ${ }^{[72]}$ In both their study and our own, we observe that once the electrode has flooded it can only be partially restored to its initial peak performance with superficial rinsing. Interestingly, we see that capacitance increases on the second run as compared to the first and remains relatively stable after subsequent uses, suggesting that it is difficult to completely remove salt crystallites that are deeply embedded in the GDE using our current washing methods. The inability to remove all residual salts aligns with the reduced breakthrough pressure values measured for post-run Ag-GDE samples that were also rinsed and dried prior to analysis (Figure 4a). Another possible, but untested, hypothesis is that crystallization irreversibly damages the porous structure of an electrode leading to higher permeability and reduced hydrophobicity. Additional electrode imaging analysis would be required to unambiguously confirm or refute this supposition. ${ }^{[74}$ We confirm with this study that periodically restoring the electrode by an ex situ rinse prolongs electrolyzer lifetime, albeit at the expense of process of feasibility. Specifically, removal and refurbishment of electrodes from within industrial electrolyzer stacks would likely require repeated equipment disassembly and reassembly leading to additional maintenance costs and compromised reliability. Ultimately, technical solutions will be needed to minimize flooding during high-current operation in gas-fed flow electrolyte systems.

\section{Conclusions}

Systematic screening of Ag-GDEs in a gas-fed, flowingelectrolyte $\mathrm{CO}_{2}$ electrolyzer revealed that electrode flooding rate correlates with applied current density. GDEs used at the lowest current density $\left(25 \mathrm{~mA} \cdot \mathrm{cm}^{-2}\right)$ demonstrate peak CO mole fraction in the product gas near $95 \%$ for over $5 \mathrm{~h}$ while those used at the highest current density $\left(196 \mathrm{~mA} \cdot \mathrm{cm}^{-2}\right)$ maintain this peak performance for less than $15 \mathrm{~min}$. Recognizing that faradaic current accelerates electrode flooding and failure, we propose that carbonation serves not only as a parasitic sink for reactant gas but also as a promoter of GDE flooding by way of crystallite precipitation within the nominally hydrophobic GDL materials. Ex situ measurements of water breakthrough pressures for electrodes used in the electrolysis experiments reveal that GDEs exposed to higher currents retain less of their initial hydrophobicity. Successful attempts to recover peak $\mathrm{CO}$ mole fractions in the product gas by rinsing electrodes affirm that carbonation and salt crystallization within the electrode are associated with performance failure. In our system, the collapse of the electrolysis performance data onto a single curve when plotted as a function of cumulative charge passed suggests that each electrode may have a material-dependent carbonate threshold that, if exceeded, will lead to precipitation and failure.

We note that reports identifying associations between carbonation and electrode failure exist within the alkaline fuel cell literature. ${ }^{[59,75-77]}$ Specifically, previous studies explored the impact of $\mathrm{CO}_{2}$ contamination on gas-fed alkaline electrolyte systems, albeit at lower concentrations. Specifically, Rolla et al. reported that feeding laboratory air to cathodes for the oxygen reduction reaction resulted in reduced current densities and gradual electrolyte flooding through the GDE along with detectable precipitates at the gas-electrolyte interface after 
several hundred hours on stream. ${ }^{[59]}$ The authors also suggested that feeding dehumidified air streams to the cathode accelerates "ageing" of both carbon and PTFE-based GDEs through electrolyte dry out and salt precipitation. Thus, although seemingly counterintuitive, humidified $\mathrm{CO}_{2}$ streams may offer a pathway to extending electrode lifetime even though the $C L$ is wetted by an aqueous electrolyte. Despite the fact that operating lifetime can be extended by adjusting operating conditions, the persistence of the carbonation problem has hampered market adoption of alkaline fuel cells for critical areas such as mobility, in which PEMFCs are now the dominant fuel cell technology. ${ }^{[78]}$ Instead, alkaline fuel cells are limited to stationary applications where $\mathrm{CO}_{2}$ scrubbing from the air feed stream is more tractable or to niche applications such as space, marine, or military where the use of pure reactant gases like $\mathrm{H}_{2}$ and $\mathrm{O}_{2}$ is practical. ${ }^{[79]}$

Although this work focuses on Ag-GDEs in contact with a flowing alkaline electrolyte for $\mathrm{CO}_{2}$ to $\mathrm{CO}$ conversion, we anticipate that persistent cathode alkalinity will broadly impact the performance of both liquid and solid-electrolyte systems. For example, current-accelerated parasitic uptake of $\mathrm{CO}_{2}$ has been reported for membrane-based $\mathrm{CO}_{2}$ electrolysis systems with both weak carbonate electrolytes ${ }^{[80]}$ or DI water ${ }^{[81]}$ fed to the anode. Polymer electrolytes feature immobile cation moieties that facilitate anion (i.e., $\mathrm{OH}^{-}, \mathrm{HCO}_{3}{ }^{-}$, and $\mathrm{CO}_{3}{ }^{2-}$ ) transport and remove the need for the mobile alkali metal cations (e.g., $\mathrm{Na}^{+}, \mathrm{K}^{+}$, $\mathrm{Cs}^{+}$) responsible for the salt precipitation that diminishes the effectiveness of GDEs in flowing electrolyte devices. However, carbonation still occurs at the alkaline interface of the cathode and anion-exchange membrane facilitating the undesirable transport of $\mathrm{CO}_{3}{ }^{2-}$ and $\mathrm{HCO}_{3}{ }^{-}$across the cell and resulting in the discharge of $\mathrm{CO}_{2}$ at the locally acidic anode. Consequently, the relationship between current density and carbonation remains relevant for this electrolyzer configuration.

We anticipate that insights from the electrochemical and ex situ results presented here for a gas-fed flowing electrolyte $\mathrm{CO}_{2}$ electrolyzer will direct attention towards the complex interplay between faradaic and homogenous reactions on and within GDEs and how these processes influence electrolyte ingress over a range of current densities and operating conditions (e.g., temperature, humidity). Quantifying electrolyte saturation in GDEs via direct operando imaging would complement this work by elucidating and perhaps confirming the physical origins of flooding at the interfaces between charged porous media and electrolytes. Furthermore, past findings from mature adjacent technologies aid in the interpretation of new experimental observations and may inspire emergent GDE designs and cell configurations for $\mathrm{CO}_{2}$ electrolysis. Specifically, incorporating application-tailored microstructures and wettability into GDEs may facilitate carbonate clearance from the gas-liquid interface that mitigates precipitation/flooding events and promotes high $\mathrm{CO}_{2}$ conversion rates for extended operation.

\section{Experimental Section}

\section{Gas-Fed Flowing Electrolyte $\mathrm{CO}_{2}$ Electrolyzer}

A gas-fed, flowing-electrolyte electrolyzer design adapted from a low-volume redox flow battery platform was used for all electrolysis experiments. ${ }^{[44]}$ The projected electrode area is 2.55 $\mathrm{cm}^{2}(1.7 \mathrm{~cm} \times 1.5 \mathrm{~cm})$ and the electrolyte chamber volume is 3.24 $\mathrm{cm}^{3}(1.7 \mathrm{~cm} \times 1.5 \mathrm{~cm} \times 1.27 \mathrm{~cm})$. A polymer-impregnated graphite plate with serpentine flow channel (MWI, G347B) serves as both the current collector and $\mathrm{CO}_{2}$ distributor to the cathode.

The working electrodes for all experiments were carbon-based, Freudenberg H23C6 (FuelCell Store) GDLs featuring a CFS with PTFE wet-proofing and a MPL. CLs were applied to the GDLs to make GDEs by spraying an ink containing $\mathrm{Ag}$ nanoparticles with a nominal size of 20-40 nm (Alfa Aesar, 45509-06), XA-9 alkaline ionomer (Dioxide Materials ${ }^{\mathrm{TM}}$ ), isopropyl alcohol (IPA), and deionized water onto the MPL with an airbrush (Speedaire, 48PX91) utilizing nitrogen as a propellant. The ink formulation was $38 \mu \mathrm{L}$ water/mg Ag, $38 \mu \mathrm{L}$ IPA/mg Ag, and $1.3 \mu \mathrm{L}$ XA-9 solution/mg $\mathrm{Ag}$ and was sonicated for $20 \mathrm{~min}$ to disperse the nanoparticles in solution prior to spraying. Each sprayed batch contained 20 GDEs. Each GDE had a total area of $2.0 \mathrm{~cm} \times 2.0$ $\mathrm{cm}$ with a catalyzed area of $1.5 \mathrm{~cm} \times 1.7 \mathrm{~cm}$. The total batch loading was determined by subtracting the initial carbon paper mass from the final mass. The average catalyst loading was measured by taking the total batch loading and dividing it by the catalyzed (active) area $\left(2.55 \mathrm{~cm}^{2}\right)$ per electrode. The catalyst loading for all GDEs was between $0.2-0.35 \mathrm{mg} \cdot \mathrm{cm}^{-2}$. SEM images show that the metal particle sizes were larger than 20-40 $\mathrm{nm}$ due to agglomeration during airbrush spray deposition (Figure $\mathrm{S} 1 \mathrm{c})$. The counter electrode for the oxygen evolution reaction (OER) is a nickel foam (Alantum, pure compressed single sheet with initial $800 \mu \mathrm{m}$ cell size) contacting a titanium (McMaster-Carr, Grade 2) current collector selected to withstand highly anodic potentials in the system. A mercury/mercury oxide $(\mathrm{Hg} / \mathrm{HgO}$, $\mathrm{CH}$ 152) reference electrode was used as an alkalinecompatibility with a $\mathrm{pH} 13.6 \mathrm{KOH}$ (Sigma-Aldrich, ACS reagent grade and/or Puriss. Grade) fill solution to match the conditions in the flowing electrolyte channel. The $\mathrm{Hg} / \mathrm{HgO}$ reference electrode was checked against a saturated calomel electrode (Fisher Scientific, nominally $+242 \mathrm{mV}$ vs SHE) dedicated for calibration.

\section{Material Flows and Pressure Regulation}

The electrolyzer was operated at ambient laboratory temperature and at low back pressure. $\mathrm{CO}_{2}$ (Airgas, Research Grade 5.0) was fed to the cell by a mass flow controller with a maximum-rated flow rate of $20 \mathrm{sccm}$ (Brooks GF40 Series). The temperature, pressure, and volumetric flow rate exiting gas stream was continuously monitored by a mass flow meter (ColeParmer, EW-17080-10, $50 \mathrm{sccm}$ maximum). Electrolyte was flowed once (i.e., "single-pass") through Norprene tubing (Saint Gobain, L/S 14) to the cell with a peristaltic pump (Masterflex® $\mathrm{L} / \mathrm{S} \AA$ Standard Digital Pump) set at $1 \mathrm{~mL} \cdot \mathrm{min}^{-1}$. All nominally $1 \mathrm{M}$ $\mathrm{KOH}$ solutions were prepared with deionized (DI) water (Millipore, 18.2 $\mathrm{M} \Omega$ ). The residual moisture content of the $\mathrm{KOH}$ pellets was not considered during preparation, so the $\mathrm{pH}$ of all solutions was measured to be 13.6 with a Metrohm $914 \mathrm{pH} /$ Conductometer. Single-pass operation was used to avoid carbonation-induced $\mathrm{pH}$ changes to $\mathrm{KOH}$ electrolyte across the GDEs during multi-hour experiments. Back pressure was maintained at the outlet of the 
gas and liquid streams with dome-loaded, low-flow rate back pressure regulators (Equilibar, LF1SNN12B-NSMP10T100F4KK) set between $1.5-2.0$ psig with compressed air to the reference port.

\section{Electrochemical Measurements}

A VSP-300 (Bio-Logic) potentiostat was used for all electrochemical measurements. The channel used for all experiments is limited to current/voltage of $\pm 500 \mathrm{~mA} / \pm 12 \mathrm{~V}$. The maximum current density for the electrolysis experiments (196 $\mathrm{mA} \cdot \mathrm{cm}^{-2}$ ) was determined by the upper current limit of the potentiostat. Data was collected and exported by EC-Lab software (Bio-Logic) to a text format (.mpt) for processing. Highfrequency resistance (HFR) between the reference and working electrodes was measured using constant voltage electrochemical impedance spectroscopy with an amplitude of $20 \mathrm{mV}$ and frequency of $100 \mathrm{kHz}$ centered on the most recently measured working electrode (cathode) potential.

\section{Product Quantification}

Product gas composition was measured using a gas chromatography (GC) system (Agilent 7890B) with HP-PLOT Q PT and HP-PLOT Molesieve columns (Agilent) and Argon carrier gas (Airgas, UHP Grade 5.0). Gas samples from a 1-mL sample loop were periodically injected into the GC by a softwarecontrolled 8-way valve driven by compressed air. A thermal conductivity detector (TCD) was used to quantify all gases of interest. The method can detect permanent gases and light hydrocarbons such as methane, ethane, and ethylene. However, only $\mathrm{CO}$ and $\mathrm{H}_{2}$ were included when calculating product gas mole fractions.

\section{Capacitance Measurements}

Capacitance is estimated by regressing the measured working electrode charging current as function of potential sweep rate. Sweep rates ranged from $50-500 \mathrm{mV} \cdot \mathrm{s}^{-1}$ in increments of 50 $\mathrm{mV} \cdot \mathrm{s}^{-1}$. The voltage range was chosen to avoid both HER and OER, which are anticipated to occur at ca. $-0.70 \mathrm{~V}$ and $+0.53 \mathrm{~V}$ vs $\mathrm{Hg} / \mathrm{HgO}(\mathrm{pH}=13.6)$, respectively. For an ideal capacitor, the charging current is a plateau, however for porous rough electrodes a non-zero resistive contribution leads to a sloped charging current. Therefore, for consistent calculations, the charging current, $i_{c}$, was determined at the center of the voltage window $(-25 \mathrm{mV}$ vs $\mathrm{Hg} / \mathrm{HgO})$ by taking the average of the absolute values of the anodic, $i_{c, A}$, and cathodic, $i_{c, C}$, charging currents according to Equation 5,

$i_{c}=\frac{\left|i_{c, A}\right|+\left|i_{c, C}\right|}{2}$

The slope of the charging current as a function of sweep rate plot is taken to be the capacitance, while the $y$-intercept is taken to be the baseline faradaic current. There is some increase in the $y$ intercept over time (Figure S15) that can be attributed to $\mathrm{H}_{2}$ oxidation. For reference, the equilibrium potential for $\mathrm{H}_{2}$ oxidation at $\mathrm{pH} 13.6$ is ca. $-0.7 \mathrm{~V}$ vs $\mathrm{Hg} / \mathrm{HgO}$, so it follows that a small amount of background faradaic current would be recorded in this voltage region when $\mathrm{H}_{2}$ is present in the GDE.

\section{Breakthrough Pressure Measurements}

Breakthrough pressures was measured using a custom-built capillary pressure imbibition apparatus (Figure S10). Samples with 7-mm diameters were punched from the parent materials and then sealed inside a custom sample holder with O-rings (McMaster-Carr, 1171N119) for each measurement. A syringe pump (Harvard Apparatus Pump 11 Pico Plus Elite) set at 7.5 $\mu \mathrm{L} \cdot \mathrm{min}^{-1}$ and loaded with two $5-\mathrm{mL}$ BD syringes was used to apply DI water pressure to one side of the porous sample, while the gas side pressure matched that of the ambient air in the laboratory. Samples were oriented with MPLs contacting the liquid chamber. A USB camera (Celestron Handheld Digital Microscope Pro) was set to record time-lapse 2.1-megapixel images of the CFS side of the GDE. The images were used to determine the locations of the liquid droplets that penetrated the sample and emerged on the air side of the sample. Liquid-side pressure was measured with a pressure transducer with an operating range of $0-1$ bar and a 4$20 \mathrm{~mA}$ current output (OMEGA, MMG015C1B3A0T3A5), transmitted via a National Instruments $D A Q$, and logged with LabView. The hydraulic head $(8.5 \mathrm{mbar})$ due to the transducer position below the sample was subtracted from all measurements.

\section{Scanning Electron Microscopy (SEM)}

Surface images of the GDE components (Figure S1) were taken using a Zeiss Merlin scanning electron microscope (SEM) equipped with an Inlens detector and operated at an accelerating voltage of $10 \mathrm{kV}$. Cross-section images (Figures 1 and S12-14) were taken using a Zeiss Gemini Ultra55 SEM equipped with secondary electron (SE) and energy dispersive spectroscopy (EDS) detectors for imaging and qualitative elemental analysis, respectively. Elemental mapping (Figures S12-14) within a $512 \times$ 400 pixel working area was performed using a $15-\mathrm{kV}$ accelerating voltage, ca. $8.5 \mathrm{~mm}$ working distance, $60.0 \mu \mathrm{m}$ aperture, and 200 $\mu$ s dwell time. A total of 20 frames were used to generate each elemental map including carbon $(C)$, oxygen $(O)$, fluorine $(F)$, potassium (K), and silver (Ag).

\section{Acknowledgements}

This work made use of the MRSEC Shared Experimental Facilities at Massachusetts Institute of Technology, supported by the National Science Foundation under award number DMR1419807, as well as the Center for Nanoscale Systems at Harvard University. The authors acknowledge the financial support of DOE SBIR Contract \#DE-SC0015173. A.F.C. acknowledges the SNSF for funding a postdoctoral fellowship (PZEZP2_172183). The authors also thank Katharine Greco and Michael Orella of the Brushett Research Group as well as Dr. Brian Skinn and Dr. Timothy Hall of Faraday Technology, Inc. for insightful discussions. 
Keywords: carbon dioxide reduction • electrochemistry • energy conversion • gas diffusion electrodes $\bullet$ wetting

[1] P. D. Luna, C. Hahn, D. Higgins, S. A. Jaffer, T. F. Jaramillo, E. H. Sargent, Science 2019, 364, eaav3506.

[2] Y. Hori, in Modern Aspects of Electrochemistry, Springer, 2008, pp. 89-189.

[3] T. Hatsukade, K. P. Kuhl, E. R. Cave, D. N. Abram, T. F. Jaramillo, Phys. Chem. Chem. Phys. 2014, 16, 13814-13819.

[4] K. P. Kuhl, E. R. Cave, D. N. Abram, T. F. Jaramillo, Energy \& Environmental Science 2012, 5, 7050.

[5] J. J. Carroll, J. D. Slupsky, A. E. Mather, Journal of Physical and Chemical Reference Data 1991, 20, 1201-1209.

[6] J. R. Rumble, Ed. , CRC Handbook of Chemistry and Physics, CRC Press/Taylor \& Francis, Boca Raton, FL, 2018.

[7] P. Lobaccaro, M. R. Singh, E. L. Clark, Y. Kwon, A. T. Bell, J. W. Ager, Phys. Chem. Chem. Phys. 2016, 18, 26777-26785.

[8] L.-C. Weng, A. T. Bell, A. Z. Weber, Phys. Chem. Chem. Phys. 2018, 20, 16973-16984.

[9] C. Chen, J. F. Khosrowabadi Kotyk, S. W. Sheehan, Chem 2018, 4, 2571-2586.

[10] R. L. Cook, R. C. MacDuff, A. F. Sammells, J. Electrochem. Soc. 1990, 137, 607-608.

[11] B. Endrődi, G. Bencsik, F. Darvas, R. Jones, K. Rajeshwar, C. Janáky, Progress in Energy and Combustion Science 2017, 62, 133-154.

[12] C.-T. Dinh, T. Burdyny, M. G. Kibria, A. Seifitokaldani, C. M. Gabardo, F. P. G. de Arquer, A. Kiani, J. P. Edwards, P. D. Luna, O. S. Bushuyev, et al., Science 2018, 360, 783-787.

[13] C.-T. Dinh, F. P. García de Arquer, D. Sinton, E. H. Sargent, ACS Energy Lett. 2018, 3, 2835-2840.

[14] H. Yang, J. J. Kaczur, S. D. Sajjad, R. I. Masel, Journal of CO2 Utilization 2017, 20, 208-217.

[15] Z. Liu, H. Yang, R. Kutz, R. I. Masel, J. Electrochem. Soc. 2018, 165, J3371-J3377.

[16] S. Verma, Y. Hamasaki, C. Kim, W. Huang, S. Lu, H.-R. M. Jhong, A. A. Gewirth, T. Fujigaya, N. Nakashima, P. J. A. Kenis, ACS Energy Lett. 2018, 3, 193-198.

[17] T. Burdyny, W. A. Smith, Energy Environ. Sci. 2019, 12, 1442-1453.

[18] A. Z. Weber, J. Newman, Chem. Rev. 2004, 104, 46794726.

[19] J. P. Owejan, J. E. Owejan, W. Gu, T. A. Trabold, T. W. Tighe, M. F. Mathias, J. Electrochem. Soc. 2010, 157, B1456B1464.

[20] J. T. Gostick, M. A. loannidis, M. W. Fowler, M. D. Pritzker, Electrochemistry Communications 2009, 11, 576-579.

[21] A. Forner-Cuenca, V. Manzi-Orezzoli, J. Biesdorf, M. E. Kazzi, D. Streich, L. Gubler, T. J. Schmidt, P. Boillat, J. Electrochem. Soc. 2016, 163, F788-F801.

[22] A. Forner-Cuenca, J. Biesdorf, A. Lamibrac, V. ManziOrezzoli, F. N. Büchi, L. Gubler, T. J. Schmidt, P. Boillat, Journal of The Electrochemical Society 2016, 163, F1038-F1048.

[23] A. Forner-Cuenca, J. Biesdorf, V. Manzi-Orezzoli, L. Gubler, T. J. Schmidt, P. Boillat, J. Electrochem. Soc. 2016, 163, F1389F1398.
[24] P. Oberholzer, P. Boillat, R. Siegrist, A. Kästner, E. H. Lehmann, G. G. Scherer, A. Wokaun, Electrochemistry Communications 2012, 20, 67-70.

[25] C. Simon, D. Kartouzian, D. Müller, F. Wilhelm, H. A. Gasteiger, J. Electrochem. Soc. 2017, 164, F1697-F1711.

[26] P. Boillat, E. H. Lehmann, P. Trtik, M. Cochet, Current Opinion in Electrochemistry 2017, 5, 3-10.

[27] Y. Nagai, J. Eller, T. Hatanaka, S. Yamaguchi, S. Kato, A. Kato, F. Marone, H. Xu, F. N. Büchi, Journal of Power Sources 2019, 435, 226809.

[28] I. V. Zenyuk, A. Lamibrac, J. Eller, D. Y. Parkinson, F. Marone, F. N. Büchi, A. Z. Weber, J. Phys. Chem. C 2016, 120, 28701-28711.

[29] K. Liu, W. A. Smith, T. Burdyny, ACS Energy Lett. 2019 , 639-643.

[30] A. Kozbial, C. Trouba, H. Liu, L. Li, Langmuir 2017, 33, 959967.

[31] S. Quu, C. A. Fuentes, D. Zhang, A. W. Van Vuure, D. Seveno, Langmuir 2016, 32, 9697-9705.

[32] KRÜSS GmbH, Wettability of Carbon Fibers Using SingleFiber Contact Angle Measurements - a Feasibility Study, 2013.

[33] D. L. Wood, C. Rulison, R. L. Borup, J. Electrochem. Soc. 2010, 157, B195-B206.

[34] F. Taherian, V. Marcon, N. F. A. van der Vegt, F. Leroy, Langmuir 2013, 29, 1457-1465.

[35] B. Kim, F. Hillman, M. Ariyoshi, S. Fujikawa, P. J. A. Kenis, Journal of Power Sources 2016, 312, 192-198.

[36] P. K. Sow, Z. Lu, H. Talebian, L. Damron, W. Mérida, J. Phys. Chem. C 2016, 120, 24794-24802.

[37] T. J. Rabbow, A. H. Whitehead, Carbon 2017, 111, 782788.

[38] S. Verma, X. Lu, S. Ma, R. I. Masel, P. J. A. Kenis, Phys. Chem. Chem. Phys. 2016, 18, 7075-7084.

[39] D. A. Salvatore, D. M. Weekes, J. He, K. E. Dettelbach, Y C. Li, T. E. Mallouk, C. P. Berlinguette, ACS Energy Lett. 2018, 3, 149-154.

[40] T. Haas, R. Krause, R. Weber, M. Demler, G. Schmid, Nature Catalysis 2018, 1, 32-39.

[41] M. Ma, B. J. Trześniewski, J. Xie, W. A. Smith, Angew. Chem. Int. Ed. 2016, 55, 9748-9752.

[42] J. Lee, J. Lim, C.-W. Roh, H. S. Whang, H. Lee, Journal of CO2 Utilization 2019, 31, 244-250.

[43] A. El-kharouf, T. J. Mason, D. J. L. Brett, B. G. Pollet, Journal of Power Sources 2012, 218, 393-404.

[44] J. D. Milshtein, J. L. Barton, R. M. Darling, F. R. Brushett, Journal of Power Sources 2016, 327, 151-159.

[45] S. Sen, S. M. Brown, M. Leonard, F. R. Brushett, J Appl Electrochem 2019, 49, 917-928.

[46] C. M. Gabardo, A. Seifitokaldani, J. P. Edwards, C.-T. Dinh, T. Burdyny, M. G. Kibria, C. P. O'Brien, E. H. Sargent, D. Sinton, Energy Environ. Sci. 2018, 11, 2531-2539.

[47] S. Ma, R. Luo, S. Moniri, Y. Lan, P. J. A. Kenis, J. Electrochem. Soc. 2014, 161, F1124-F1131.

[48] B. Kim, S. Ma, H.-R. Molly Jhong, P. J. A. Kenis, Electrochimica Acta 2015, 166, 271-276.

[49] K. Wu, E. Birgersson, B. Kim, P. J. A. Kenis, I. A. Karimi, J. Electrochem. Soc. 2015, 162, F23-F32. 
[50] S. Ma, M. Sadakiyo, R. Luo, M. Heima, M. Yamauchi, P. J. A. Kenis, Journal of Power Sources 2016, 301, 219-228.

[51] S. Verma, X. Lu, S. Ma, R. I. Masel, P. J. A. Kenis, Phys. Chem. Chem. Phys. 2016, 18, 7075-7084.

[52] D. W. Keith, G. Holmes, D. St. Angelo, K. Heidel, Joule 2018, 2, 1573-1594

[53] K. G. Schulz, U. Riebesell, B. Rost, S. Thoms, R. E. Zeebe, Marine Chemistry 2006, 100, 53-65.

[54] A. D. Santamaria, P. K. Das, J. C. MacDonald, A. Z. Weber, J. Electrochem. Soc. 2014, 161, F1184-F1193.

[55] Y. Duan, D. R. Luebke, H. W. Pennline, B. Li, M. J. Janik, J. W. Halley, J. Phys. Chem. C 2012, 116, 14461-14470.

[56] M. D. Eisaman, L. Alvarado, D. Larner, P. Wang, B. Garg, K. A. Littau, Energy Environ. Sci. 2011, 4, 1319-1328.

[57] J. D. Watkins, N. S. Siefert, X. Zhou, C. R. Myers, J. R. Kitchin, D. P. Hopkinson, H. B. Nulwala, Energy Fuels 2015, 29, 7508-7515.

[58] W. A. Rigdon, T. J. Omasta, C. Lewis, M. A. Hickner, J. R. Varcoe, J. N. Renner, K. E. Ayers, W. E. Mustain, J. Electrochem. En. Conv. Stor. 2017, 14, 020701-020701-8.

[59] A. Rolla, A. Sadkowski, J. Wild, P. Zóltowski, Journal of Power Sources 1980, 5, 189-196.

[60] S. Veran-Tissoires, M. Marcoux, M. Prat, Phys. Rev. Lett. 2012, 108, 054502.

[61] L.-C. Weng, A. T. Bell, A. Z. Weber, Energy Environ. Sci. 2019, 12, 1950-1968.

[62] P. M. Dunlap, S. R. Faris, Nature 1962, 196, 1312-1313.

[63] J. Benziger, J. Nehlsen, D. Blackwell, T. Brennan, J. Itescu, Journal of Membrane Science 2005, 261, 98-106.

[64] J. T. Gostick, M. W. Fowler, M. A. loannidis, M. D. Pritzker, Y. M. Volfkovich, A. Sakars, Journal of Power Sources 2006, 156, 375-387.

[65] J. T. Gostick, M. A. loannidis, M. W. Fowler, M. D. Pritzker, Electrochemistry Communications 2008, 10, 1520-1523.

[66] T. G. Tranter, J. T. Gostick, A. D. Burns, W. F. Gale, Transp Porous Med 2018, 121, 597-620.
[67] S. Verma, U. O. Nwabara, P. J. A. Kenis, in Nanocarbons for Energy Conversion: Supramolecular Approaches (Ed.: N. Nakashima), Springer International Publishing, Cham, 2019, pp. 219-251.

[68] J. T. Gostick, M. A. loannidis, M. W. Fowler, M. D. Pritzker, Journal of Power Sources 2009, 194, 433-444.

[69] A. Lamibrac, J. Roth, M. Toulec, F. Marone, M. Stampanoni, F. N. Büchi, J. Electrochem. Soc. 2016, 163, F202-F209.

[70] H.-R. "Molly" Jhong, F. R. Brushett, P. J. A. Kenis, Adv. Energy Mater. 2013, 3, 589-599.

[71] G. S. Shapoval, A. A. Pud, P. V. Zamotayev, A. A. Kachan, Polymer Science U.S.S.R. 1985, 27, 2427-2431.

[72] B. Endrődi, E. Kecsenovity, A. Samu, F. Darvas, R. V. Jones, V. Török, A. Danyi, C. Janáky, ACS Energy Lett. 2019, 4, 17701777.

[73] B. De Mot, J. Hereijgers, M. Duarte, T. Breugelmans, Chemical Engineering Journal 2019, 378, 122224.

[74] N. Shahidzadeh-Bonn, J. Desarnaud, F. Bertrand, X. Chateau, D. Bonn, Phys. Rev. E 2010, 81, 066110.

[75] J. Lamminen, J. Kivisaari, M. J. Lampinen, M. Viitanen, J. Vuorisalo, J. Electrochem. Soc. 1991, 138, 905-908.

[76] M. A. Al-Saleh, S. Gültekin, A. S. Al-Zakri, H. Celiker, J Appl Electrochem 1994, 24, 575-580.

[77] M. S. Naughton, F. R. Brushett, P. J. A. Kenis, Journal of Power Sources 2011, 196, 1762-1768.

[78] N. H. Behling, in Fuel Cells (Ed.: N.H. Behling), Elsevier, 2013, pp. 37-51.

[79] M. L. Perry, T. F. Fuller, J. Electrochem. Soc. 2002, 149, S59-S67.

[80] G. O. Larrazábal, P. Strøm-Hansen, J. P. Heli, K. Zeiter, K. T. Therkildsen, I. Chorkendorff, B. Seger, ACS Appl. Mater. Interfaces 2019, DOI 10.1021/acsami.9b13081.

[81] Z. Yin, H. Peng, X. Wei, H. Zhou, J. Gong, M. Huai, L. Xiao, G. Wang, J. Lu, L. Zhuang, Energy Environ. Sci. 2019, 12, 24552462. 
Entry for the Table of Contents (Please choose one layout)

Layout 1:

\section{FULL PAPER}

\section{Abstract}

Introduction

Results and Discussion

Conclusions

Experimental Section

Acknowledgements

References

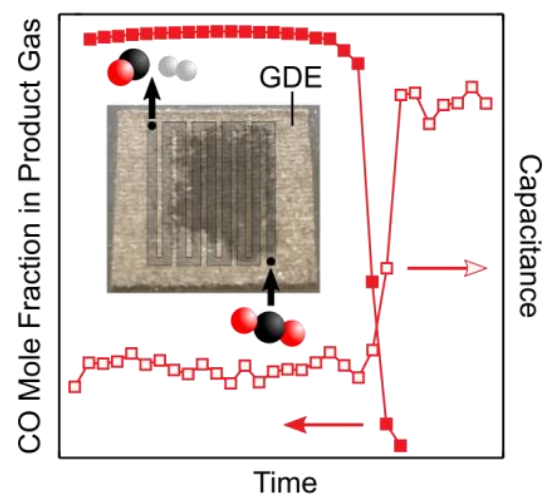

M. E. Leonard, L. E. Clarke, Prof. Dr. A. Forner-Cuenca, Dr. S. M. Brown, Prof. Dr. Fikile R. Brushett*

$$
\text { Page No. - Page No. }
$$

Investigating Electrode Flooding in a Flowing Electrolyte, Gas-Fed Carbon Dioxide Electrolyzer

Layout 2:

\section{FULL PAPER}

((Insert TOC Graphic here; max. width: $11.5 \mathrm{~cm}$; max. height: $2.5 \mathrm{~cm}$ ))

Author(s), Corresponding Author(s)*

Page No. - Page No.

Title

Text for Table of Contents 